\begin{abstract}
Iranica
Abstracta Iranica Revue bibliographique pour le domaine irano-aryen

Volume 34-35-36 | 2017

Comptes rendus des publications de 2011-2013
\end{abstract}

\title{
Daniel De Smet. La philosophie ismaélienne. Un ésotérisme chiite entre néoplatonisme et gnose
}

\section{Mathieu Terrier}

\section{(2) OpenEdition}

1 Journals

\section{Édition électronique}

URL : http://journals.openedition.org/abstractairanica/41351

DOI : 10.4000/abstractairanica.41351

ISSN : 1961-960X

Éditeur :

CNRS (UMR 7528 Mondes iraniens et indiens), Éditions de l'IFRI

\section{Référence électronique}

Mathieu Terrier, « Daniel De Smet. La philosophie ismaélienne. Un ésotérisme chiite entre néoplatonisme et gnose », Abstracta Iranica [En ligne], Volume 34-35-36 | 2017, document 2, mis en ligne le 15 juillet 2016, consulté le 27 septembre 2020. URL : http://journals.openedition.org/abstractairanica/41351 ; DOI : https://doi.org/10.4000/abstractairanica.41351

Ce document a été généré automatiquement le 27 septembre 2020.

Tous droits réservés 


\title{
Daniel De Smet. La philosophie ismaélienne. Un ésotérisme chiite entre néoplatonisme et gnose
}

\author{
Mathieu Terrier
}

\section{RÉFÉRENCE}

Daniel De Smet. La philosophie ismaélienne. Un ésotérisme chiite entre néoplatonisme et gnose. Paris, Les éditions du Cerf, 2012, $190 \mathrm{p}$.

1 Cet ouvrage concis et très dense entend réparer la méconnaissance du rôle du chiisme ismaélien dans l'intégration à l'Islam de nombreuses traditions philosophiques et religieuses tardo-antiques. Pour ce faire, l'A. nous expose les réponses des penseurs ismaéliens carmathes, fatimides et tayyibites, aux grandes questions cosmologiques, théologiques et eschatologiques qui sont celles de la philosophie et des religions monothéistes.

Le premier chapitre définit l'ismaélisme, dans sa diversité, comme un ésotérisme chiite, avec son image du monde dominée par le concept de "sympathie universelle ", son rapport ambigu aux sciences et à la philosophie, en particulier la gnose et le néoplatonisme. Les chapitres suivants analysent la pensée ismaélienne du Moyen Âge dans ses grands champs thématiques. La théologie d'abord, où la conception ismaélienne radicale du tawhīd entraîne la notion d'un Dieu "Instaurateur " absolument transcendant, inaccessible et inconnaissable, fait l'objet du chapitre II. La cosmogonie et la théogonie sont analysées dans le chapitre III, avec le mythe philosophique de l'Intellect-démiurge orgueilleux, le système dynamique des Intellects successifs émanés à partir du premier être instauré, et le " drame dans le ciel » du troisième Intellect rétrogradé au dixième rang, cause de l'apparition du monde sublunaire. Le chapitre IV étudie l'herméneutique philosophique ismaélienne du Coran et des Livres antérieurs, en particulier sur le récit de la chute d'Adam et le symbole de 
l'arbre du Bien et du Mal ; basée sur la distinction aristotélicienne de la première et de la seconde perfection, l'exégèse ismaélienne décrit l'histoire prophétique comme procès d'actualisation de l'intellect humain et l'histoire cosmique comme procès d'actualisation de l'Intellect en puissance. Cette théorie a pour conséquence doctrinale la transmigration des âmes, soutenue de différentes manières par les auteurs ismaéliens médiévaux, objet du chapitre V. Sur l'Âme universelle et la relation de l'âme humaine à elle, ces penseurs réactivent les débats et les thèses des néoplatoniciens pour des enjeux nouveaux, développant d'une part, annexée à la prophétologie et à l'imamologie, une conception complexe de la transmigration de l'Intellect, et d'autre part, pour le commun des hommes, des théories diverses des renaissances successives des âmes, de métempsycoses accompagnées de métamorphoses. L'eschatologie tayyibite, résumée dans le chapitre VI, noue tous les fils de la métaphysique, de la cosmologie et de la prophétologie ismaéliennes, en s'appuyant sur une étonnante " théorie de l'évolution » développée au X ${ }^{\mathrm{e}}$ s. par les "IHWwān al-ṣafā"'. En conclusion, l'A. soutient que la pensée ismaélienne mérite bien le nom de "philosophie » tout en étant irréductible à la falsafa, une thèse dont on peut dire que l'ouvrage démontre brillamment la justesse.

\section{AUTEURS}

\section{MATHIEU TERRIER}

CNRS, Paris 